\title{
Examining the Correlation Between Stress and Disordered Eating
}

\author{
Wenyu Liu ${ }^{1}$ \\ ${ }^{1}$ Beijing International Bilingual Academy, Beijing 100000, China, lwy20040410@gmail.com
}

\begin{abstract}
Many people are struggle with disordered eating behavior and simultaneously developed serious mental illnesses. Disordered Eating is caused by multiple factors including psychological, biological, and social aspects. Psychological aspects that might seem unrelated to specific eating including generalized stress may play a causal role. The present study experimentally investigated the relationship between stress level and disordered eating. Participants $(\mathrm{N}=38)$ were given two questionnaires (Depression Anxiety and Stress Scales; Eating Disorder Examination Questionnaire) that assessed stress level and eating disorder respectively. Demographic information (age and gender) was recorded lastly. From previous research, the hypothesis that there is a positive correlation between the level of disordered eating and level of stress. The data gathered from the questionnaires supported the hypothesis (Pearson $\mathrm{r}(38)=0.575, \mathrm{p}<0.001$ ). Additional analyses further investigated the correlation between each subscale from each questionnaire. Results indicated that disordered eating is closely related to stress. This relationship has a great implications for the clinical treatment for eating disorders.
\end{abstract}

Keywords: eating disorder, stress

\section{INTRODUCTION}

Food is one of the basic human survival needs and pleasure. However, many people stuggle to manage its consumption resulting in unhealthy eating habits and behaviors. According to the statistics, the prevalence of eating disorders increased from $3.5 \%$ for $2000-2006$ to $7.8 \%$ for 2013-2018. Therefore, studies on eating disorders highlight a considerable benefit to public health.

Disordered eating refers to abnormal eating patterns and food behaviors, which cause emotional disruption.
Although people with disordered eating may not necessarily meet the clinical diagnosis criteria for eating disorder because of lower severity, disordered eating is still problematic and includes some symptoms of eating disorders. There are mainly three types of eating disorders recognized by the American Psychological Association (APA): Table 1 summarizes the diagnosis criteria, risk factors, prevalence, and consequences for three eating disorders according to the Diagnostic and Statistical Manual of Mental Disorders-5th edition[1], statistics from National Institute of Mental Health [2], and risk factors from National Eating Disorders Association [3]. 
Table 1 Eating Disorders Classification (Anorexia Nervosa, Bulimia Nervosa and Binge Eating Disorder)

\begin{tabular}{|c|c|c|c|c|}
\hline $\begin{array}{l}\text { Type of } \\
\text { Eating } \\
\text { Disorder }\end{array}$ & Diagnosis Criteria & Risk Factors & Prevalence & Consequences \\
\hline $\begin{array}{l}\text { Anorexia } \\
\text { Nervosa } \\
\text { (AN) }\end{array}$ & $\begin{array}{l}\text { A. Extreme restriction of energy intake that } \\
\text { is unhealthy. } \\
\text { B. Intense fear of gaining weight or } \\
\text { becoming fat. } \\
\text { C. Experiencing weight or shape } \\
\text { distortion. }\end{array}$ & $\begin{array}{l}\text { Temperament: } \\
\text { Anxious or obsessional traits in } \\
\text { childhood. } \\
\text { Environment } \\
\text { The way of valuing thinness in } \\
\text { different cultures and settings. } \\
\text { Gene and physiology: } \\
\text { The risk of having AN increases } \\
\text { when the first-degree biological } \\
\text { relatives of individuals with AN. }\end{array}$ & $\begin{array}{l}\text { AN is more common in } \\
\text { female than male: } 12 \text { - } \\
\text { month prevalence of AN } \\
\text { among young females is } \\
\text { about } 0.4 \% \text {; the } \\
\text { prevalence in male is } \\
\text { unknow. }\end{array}$ & \begin{tabular}{l}
\multicolumn{2}{l}{ Social isolation. } \\
Failure in \\
academic \\
studies and \\
career.
\end{tabular} \\
\hline $\begin{array}{l}\text { Bulimia } \\
\text { Nervosa } \\
\text { (BN) }\end{array}$ & $\begin{array}{l}\text { A. Recurrent episodes of eating in a great } \\
\text { amount of food with the feeling of losing } \\
\text { control overeating. } \\
\text { B. Recurrent inappropriate compensatory } \\
\text { behavior to prevent gaining weight } \\
\text { C. Criteria A and B occur at least once a } \\
\text { week for } 3 \text { months } \\
\text { D. influence on self-evaluation caused by } \\
\text { body shape and weight } \\
\text { E. Disturbance occurs except from } \\
\text { episodes of AN. }\end{array}$ & $\begin{array}{l}\text { Temperament: } \\
\text { Weight concerns, low self-esteem, } \\
\text { depressive symptoms, social } \\
\text { anxiety disorder and overanxious } \\
\text { disorder of childhood } \\
\text { Environment: } \\
\text { The way of valuing thinness in } \\
\text { different cultures and settings. } \\
\text { Experiencing childhood sexual or } \\
\text { physical abuse. } \\
\text { Gene and physiology: } \\
\text { Childhood obesity and early } \\
\text { pubertal maturation. } \\
\text { Family transmission. } \\
\text { Genetic vulnerabilities. } \\
\text { Course modifiers: } \\
\text { Psychiatric comorbidity. }\end{array}$ & $\begin{array}{l}\text { 12-month prevalence of } \\
\text { BA among young } \\
\text { females is } 1 \%-1,5 \% \text { and } \\
\text { most significant in older } \\
\text { adolescence and young } \\
\text { adulthood. The } \\
\text { prevalence is less } \\
\text { common in males. }\end{array}$ & $\begin{array}{l}\text { Several role } \\
\text { impairments } \\
\text { (affect social } \\
\text { life). }\end{array}$ \\
\hline $\begin{array}{l}\text { Binge } \\
\text { Eating } \\
\text { Disorder } \\
\text { (BED) }\end{array}$ & $\begin{array}{l}\text { A. recurrent episodes of eating in a great } \\
\text { amount of food with the feeling of losing } \\
\text { control overeating. } \\
\text { B. meeting three or more followings: } \\
\text { Eating more rapidly than normal. } \\
\text { Eating until feeling uncomfortable. } \\
\text { Eating a large amount of food despite no } \\
\text { feeling of hungry. } \\
\text { Eating alone because of the } \\
\text { embarrassment caused by the amount of } \\
\text { food consumption } \\
\text { Feeling disgusted, depressed or guilty } \\
\text { after eating. } \\
\text { D. marketed distress. } \\
\text { E. the binge eating occurs at least once a } \\
\text { week for } 3 \text { months. } \\
\text { F. no association with inappropriate } \\
\text { compensatory behaviors. }\end{array}$ & $\begin{array}{l}\text { Gene and physiology: } \\
\text { Family transmission. }\end{array}$ & $\begin{array}{l}\text { 12-month prevalence of } \\
\text { BED amount US adult } \\
\text { females is } 1.6 \% \text { and } \\
0.8 \% \text { for males. } \\
\text { The prevalence is same } \\
\text { among females from } \\
\text { different racial or ethnic } \\
\text { groups. } \\
\text { The prevalence is high } \\
\text { in people who seek } \\
\text { weight-loss treatment. }\end{array}$ & $\begin{array}{l}\text { Social role } \\
\text { adjustment } \\
\text { problems, } \\
\text { healthy } \\
\text { problems, low } \\
\text { life satisfaction, } \\
\text { increased } \\
\text { medical } \\
\text { morbidity and } \\
\text { mortality and } \\
\text { increased } \\
\text { health car. } \\
\text { Weight gain and } \\
\text { obesity. }\end{array}$ \\
\hline
\end{tabular}

As the above discusses, many factors may contribute to the symptoms of eating disorders, which include biological, psychological, and social influences. Stress is an important risk factor in affecting an individual's eating behaviors, referring to "Stress Eating".
Lazarus and Folkman proposed that "psychological stress is a particular relationship between the person and the environment that is appraised by the person as taxing or exceeding his or her resources and endangering his or her well-being" (p.19) [4]. In the short term, stress can lead to a decrease in appetite. Stress triggers a "fight or flight "response, activating the sympathetic nervous 
system [5]. The activation can stimulate cardiac activity, renal vasoconstriction, and skeletal muscle blood flow. These activities require high energy. Other behaviors like eating, digesting, and reproduction included in parasympathetic activities are inhibited to conserve energy. Therefore, appetite and eating behaviours may be expected to decrease from of short-term stress.

However, in long term, stress leads to the opposite eating behavior. Stress plays a great role in coordinating the hypothalamic-pituitary-adrenal (HPA) axis, a hormone-triggers-hormone pathway. Stress stimulates the release of corticotropin-releasing factor (CRF) from the paraventricular nucleus (PVN). CRF in turn leads to the release of adrenocorticotropic hormone (ACTH) from the pituitary gland. ACTH triggers the stimulation of glucocorticoids (GCs) including cortisol from the adrenal cortex. GCs can mediate the influence of stress on CRF by acting on the hypothalamus [6]. However, under continuous stress stimulation, the function of the HPA axis is disrupted, altering glucose metabolism and insulin secretion.

The release of cortisol enhances the release of dopamine from the ventral striatum and other striatal regions. Dopamine (DA) is a critical neurotransmitter in the rewarding system that gives humans a strong motivation (to eat) and less control on inhibition [7]. The strengthened rewarding sensations experienced by individuals under chronic stress might contribute to engagement increased eating, especially consuming high-fat, high-sugar foods that can provide comfort to counteract negative states. Cortisol-induced insulin further increases the intake of fat and gaining weight [8].

The relationship between food and emotional state was demonstrated by Wurtman and Wurtman who found that consumption of foods rich in carbohydrates can further help people to regulate moods, especially giving a sense of satisfaction and happiness when the one individual is in a stressful situation [9]. Serotonin plays a major role in controlling positive mood and carbohydrate consumption increases serotonin release. Therefore, people who are stressed are likely to take in carbohydrates to compensate for negative feelings [10-14].

The current study examines the stress level and disordered eating in a sample population. Under the stressful global recession due to pandemic, current research gives real-time investigation into the disordered eating. The results can shed light on future implications of developing therapies based on the relationship between stress and disordered eating, promoting public health in a wide range of populations.

\section{Hypotheses}

Null Hypothesis $\mathbf{H}_{\mathbf{0}}$ : There is a non-significant Person correlation between the level of disordered eating and the level of stress.

Alternative hypothesis $H_{1}$ : There is a significant positive Pearson correlation between the level of disordered eating and the level of stress

\section{METHODS}

\subsection{Participants}

Participants $(n=40)$ in this study were recruited online through opportunity sampling $(\mathrm{n}=11)$ and recruited through Amazon Turk $(n=29)$. for which, only Mechanical Turk Masters who were identified high performing workers and received Masters Qualification were able to participate (honorarium of $\$ 0.5$ was offered). After the data was collected and, 38 sets of data were used. Participants were from different age groups: most participants were $30-45$ years old (45\%) and $15-30$ years old $(42 \%) ; 4$ participants were more than 45 years old $(10 \%)$ and 1 was $0-15$ years old $(3 \%)$ (Figure 1). 20 were female and 18 were male.

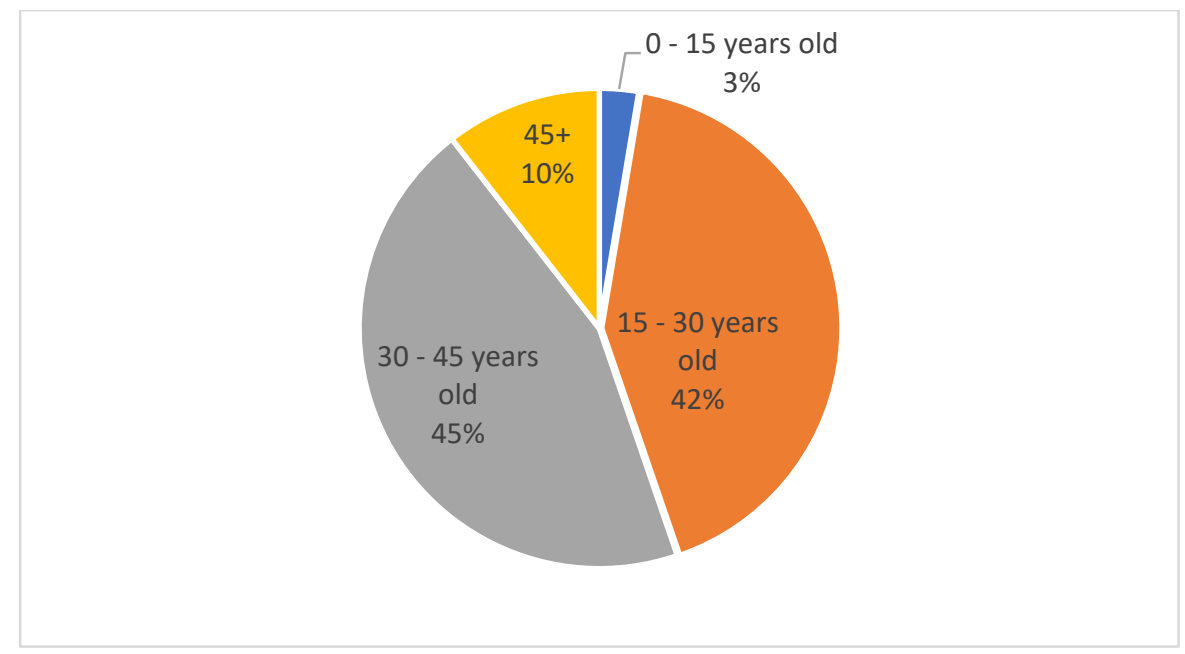

Figure 1 The demographic information of participants 


\subsection{Procedure}

Participants in this study were recruited in two waysopportunity sampling and volunteering sampling. The questionnaire was programmed in Gorilla ${ }^{T M}$ and a questionnaire web link was shared on the social media platform (WeChat) and on MTurk. . The aim of the study and ways to assess stress, anxiety, depression level, and disordered eating were told to the participants before they entering the questionnaire website. All data was collected and anonymously coded.

\subsection{Measures}

Questionnaires measured stress level and disordered eating were measured through the following questionnaires respectively. In addition to these two variables, anxiety level, and depression levels were also measured through these two questionnaires.

Depression Anxiety and Stress Scales (DASS-21). DASS-21 is a quantitative measure of distress. It was developed by researchers from the University of New South Wales [15]. It examines three aspects of depression, anxiety, and stress. The original questionnaire has 42 -item. The current study used the short version with 21 items that have 7 items for each scale. 4-point scales are used to rate the extent to which they have experienced the descriptive statement over the past week. The rating scales ranging from 0 , meaning "the statement did not apply to me at all", to 3, meaning "the statement applied to me very much, or most of the time". One example on the DASS-21 is that "I tended to over-react to situations", which assesses the stress level, especially for "over-aroused, tense". For research uses, it can discriminate three related states of depression, anxiety, and stress. It can not only be carried out with non-clinical samples but also be used in normal adolescents and adults. The current study used this selfreport measure to assess levels of stress, anxiety, and depression. It has a high internal reliability validated by previous research [16]. For the one of the version of
DASS-21 (Vietnamese), the internal consistency of the Stress scale is 0.7 and the one for overall scale is 0.8 ; the sensitivity to detect depression and anxiety in women is $79.1 \%$, which demonstrates that DASS-21 is a comprehensive and sensitive tool for screening anxiety, depression and stress in a sample.

Eating Disorder Examination Questionnaire (EDE-Q). It is a 28-item self-reported questionnaire from the interview Eating Disorder Examination (EDE) to assess the severity of eating disorder through four related subscales (Restraint, Eating Concern, Shape Concern, and Weight Concern) and one global score. It can be used with anyone over the age of 14 . For example, one of the items of EDE-Q is "Have you gone for long periods (8 waking hours or more) without eating anything at all to influence your shape or weight?", which assessed the subject's Restraint. The overall correlation coefficient effect size is 0.76 and the overall Cohen's effect size is 0.62 in participants who have high scoring on the questionnaire [17]. This questionnaire also has a high internal consistency and 2-week test-retest reliability [18].

Demographics Questionnaire. Age and gender of participants were also collected.

\section{RESULTS}

All analyses were conducted in Excel (version number). Correlations between questionnaires were calculated and are presented in Table 2. It was hypothesized that individuals with higher stress levels correlate with higher disordered eating: there is a significant positive correlation between disordered eating and stress. To test this hypothesis, correlation and regression test were conducted between the stress scale measured by the DASS-21 and global score (the sum of scores for four subscales and divide by 4) for disordered eating measured by EDE-Q. We used an alpha level of 0.05 for all statistical tests. Results showed that this correlation was positively significant $(r(38)=0.575), p<$ $0.001)$. This correlation suggests that $33 \%$ variation of disordered eating is shared by stress level $\left(R^{2}=0.331\right)$ as demonstrated in the Figure 2.
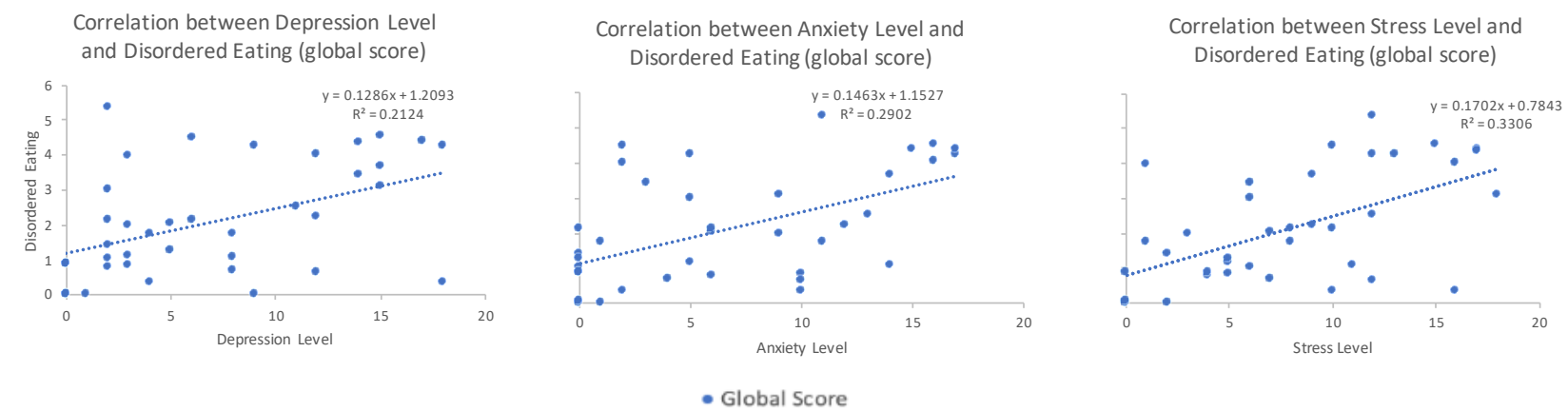

Figure 2 Correlation between Depression, Anxiety and Stress Level and Disordered Eating (global score) 
Other exploratory analyses were then conducted to analyze the items in EDE-Q and DASS-21 to determine if specific subscales correlate with stress level. Four subscales in the EDE-Q are restraint, eating concern, shape concern, weight concern. Among these subscales, the stress subscale is significantly correlated with eating concern $(r(38)=0.678, p<0.001)$; while the stress subscale is less significantly correlated with restraint $(r$ $(38)=0.347, p=0.033)$.

The correlations between anxiety, depression, and disordered eating were also examined in data analyses. The stress subscale is significantly correlated with anxiety and depression subscales respectively ( $r$ (38) $=0.763, p<0.0013 ; r(38)=0.757, p<0.001)$. The anxiety subscale is significantly correlated with the global score of eating disorders $(r(38)=0.539, p<0.001)$. $29 \%$ variation of disordered eating is explained by anxiety level $\left(R^{2}=0.290\right)$ as demonstrated in the Figure
2. However, the depression subscale is less significantly correlated with the global score of eating disorder $(r$ $(38)=0.461, p<0.001) .21 \%$ variation of disordered eating is explained by depression level $\left(R^{2}=0.212\right)$ as demonstrated in the Figure 2. Therefore, comparing with all three subscales measured in DASS-21, overall disordered eating is most significantly correlated with stress level.

For other subscales measured in EDE-Q, eating concern is most significantly correlated with one's mental state (with stress: $r(38)=0.678, p<0.001$; with anxiety: $r(38)=0.668, p<0.001$; with depression: $r(38)=0.539$, $p<0.001)$. In contrast, restraint is less correlated with the mental state (with stress: $r(38)=0.346, p=.0332$; with anxiety: $r(38)=0.227, p=0.171$; with depression: $r(38)$ $=0.347, p=0.0327)$. Overall, all EDE-Q items are significantly correlated $(r(38)>0.613, p<0.01)$.

Table 2 Correlations between subscales of DASS-21 and EDE-Q

\begin{tabular}{|c|c|c|c|c|c|c|c|c|}
\hline Variable & 1 & 2 & 3 & 4 & 5 & 6 & 7 & 8 \\
\hline 1. Stress & - & & & & & & & \\
\hline 2. Anxiety & $0.763^{* *}$ & - & & & & & & \\
\hline 3. Depression & $0.757^{* *}$ & $0.703^{* *}$ & - & & & & & \\
\hline 4. Restraint & $0.346^{*}$ & 0.227 & $0.347^{*}$ & - & & & & \\
\hline 5. Eating Concern & $0.678^{* *}$ & $0.668^{* *}$ & $0.539^{* *}$ & $0.613^{* *}$ & - & & & \\
\hline 6. Shape Concern & $0.552^{* \star}$ & $0.533^{* *}$ & $0.452^{* *}$ & $0.674^{\star *}$ & $0.886^{* *}$ & - & & \\
\hline 7. Weight Concern & $0.521^{* *}$ & $0.541^{* *}$ & $0.339^{*}$ & $0.687^{* *}$ & $0.889^{* *}$ & $0.924^{\star *}$ & - & \\
\hline 8. Total EDE-Q(Global Score & $0.575^{\star \star}$ & $0.539^{* *}$ & $0.461^{*}$ & $0.816^{\star *}$ & $0.928^{* *}$ & $0.953^{* *}$ & $0.957^{* *}$ & - \\
\hline
\end{tabular}

Note: $* p<0.05, * p<0.01, n=38$

\section{DISCUSSION}

The current study aimed to examine this correlation in non-clinical samples and found the correlation between stress and disordered eating. The hypothesis is supported that stress has a correlational relationship with disordered eating. Further analyses indicate that stress level significantly correlated with anxiety and depression measured by DASS-21 and all subscales in EDE-Q (eating concern, shape concern, and weight concern) except for restraint. Moreover, although the correlation between disordered eating and anxiety may have been weaker than with stress, it is still observed. Anxiety level is significantly correlated with all subscales in DASS-21 and subscales of eating concern, shape concern and weight concern measured by EDE-Q. Stress, anxiety, and depression measured in DASS-21 were significantly correlated. Four subscales and global scores of EDE-Q are also significantly correlated. Therefore, the mental state is closely correlated with the disordered eating.
Previous research had examined the relationship between stress and disordered eating and suggested possible correlations with disordered eating [10-14]. The results are consistent with previous studies that investigate the relationship between stress and disordered eating $[13,14,19]$, which validated the current study. Moreover, results support the correlation between anxiety and disordered eating, which was insignificant in previous research that examined this relationship in college women but consistent with other research that carried out in a sample of female athletes $[14,20]$. Further analyses in subscales indicate that anxiety also significantly correlates with disordered eating.

However, while the findings of the current study support a correlation, it would be valuable to understand whether stress leads to disordered eating or whether eating leads to stress. rather than a causal relationship. On the one hand, chronic stress induced by acculturation, low self-esteem, and life transitions might stimulate the immoderate appetite $[14,21]$; On the other hand, longterm disordered eating habits caused by losing weight, 
imbalanced diet, keeping body image may lead to stress and anxiety [22]. There are also stress models into Anorexia Nervosa, which strengthens the factor of stress in disordered eating [23]. Therefore, the relationship between stress and disordered eating is more likely to be mutual.

The study contained a relatively small sample, but discovered strong and statistically reliable correlations, attesting the size of the effect under observation. Comparing the demographics of my sample with that in the literature the comparison that is most apt is the majority age group in $15-45$ years old (87\%). It would be better to set a target population. Also, the demographic information about each participant is limited: only age and gender information are acquired. Gathering information like career, cultures, and races can further develop a detailed picture of participants. However, due to the restricted way of distributing questionnaires and collecting data, the current study gives meaningful insight on disordered food behaviors as well as confirmed previous research. Again, the responses from questionnaires were from a non-clinical sample, meaning that the results only shed light on disordered eating. Individuals with eating disorders have a higher frequency and level of severity in disordered behaviors, diagnosis by DSM-5. IN the clinical population, the factors related to the disorder would be much more complex and need to be diagnosed based on individual difference

\section{IMPLICATION}

Food should be an enjoyment rather than a source of stress. The revealed relationship between mental states and disordered eating has high applicability in clinical treatment for emotional eating. For people with emotional eating, they are likely to struggle with an unhealthy cycle: although binge eating might bring satisfaction immediately, they are likely to feel increasingly guilty and hard to control the appetite. Therefore, using eating as a vent for feelings is still inappropriate and people need a healthier way to release stress and anxiety. Except for mindfulness, balanced sleeping, and exercise, some programs like Cognitive behavior treatment (CBT) and Dialectal behavior therapy (DBT) that aim to improve emotional regulation, distress tolerance, and mindfulness are likely to be effective in patients with a stress-induced eating disorder on the daily bases. They help individuals to learn how to cope and accept negative feelings in a healthy way instead of through uncontrolled eating [24]. Future research can focus on these programs to validate their effectiveness in varied samples.

For individuals with Anorexia Nervosa (AN), addressing psychological burdens in therapies is also advisable. BMI is considered the most influential factor in developing anorexia nervosa. Patients with $\mathrm{AN}$ at least have a BMI less or equal to $17 \mathrm{~kg} / \mathrm{m} 2$ (DSM-5). After examining patients with AN, however, Schmalbach et al. stated that it is reasonable to take other psychological variables as factors including stress appraisal [25]. The empirical data also showed that AN symptom is more related to psychological stress rather than BMI Therefore, stress-coping skills are essential to the process of recovery from most kinds of eating disorders. More research can be conducted on the relationship between stress and specific eating disorders in a wider range of populations.

\section{CONCLUSION}

The current study examined the relationship between the level of disordered eating and stress. The information from participants $(n=38)$ is collected through Eating Disorder Examination Questionnaire (EDE-Q) and Depression Anxiety and Stress Scales (DASS-21). Results supported the hypothesized correlation between the level of disordered eating and stress. In addition, the level of anxiety is correlated with the level of disordered eating in further analysis. The current study demonstrates the relationship between mental state and disordered eating, which has an implication on the clinical treatment of eating disorder. However, the direction of this correlation is yet to be determined. Future research can investigate this causal relationship in a larger and varied sample.

\section{REFERENCES}

[1] American Psychiatric Association. (2013). Diagnostic and Statistical Manual of Mental Disorders, 5th Edition: DSM-5 (5th ed.). American Psychiatric Publishing.

[2] NIMH » Eating Disorders. (2017, November 1). National Institute of Mental Health. https://www.nimh.nih.gov/health/statistics/eatingdisorders

[3] National Eating Disorders Association. (2018, $\begin{array}{llll}\text { August } & 3 \text { ). Risk }\end{array}$ https://www.nationaleatingdisorders.org/riskfactors

[4] Lazarus, R. S., \& Folkman, S. (1984). Stress, Appraisal, and Coping (1st ed.). Springer Publishing Company.

[5] Goldstein, D. S. (1987). Stress-induced activation of the sympathetic nervous system.

[6] Yau, Y. H., \& Potenza, M. N. (2013). Stress and eating behaviors. Minerva endocrinologica, 38(3), 255-267.

[7] Wand, G. S., Oswald, L. M., McCaul, M. E., Wong, D. F., Johnson, E., Zhou, Y., Kuwabara, H., \& Kumar, A. (2007). Association of Amphetamine- 
Induced Striatal Dopamine Release and Cortisol Responses to Psychological Stress. Neuropsychopharmacology, 32(11), 2310-2320. https://doi.org/10.1038/sj.npp.1301373

[8] la Fleur, S. E., Akana, S. F., Manalo, S. L., \& Dallman, M. F. (2004). Interaction between Corticosterone and Insulin in Obesity: Regulation of Lard Intake and Fat Stores. Endocrinology, 145(5), 2174-2185. https://doi.org/10.1210/en.2003-1359

[9] Wurtman, R. J., \& Wurtman, J. J. (1995). Brain Serotonin, Carbohydrate-Craving, Obesity and Depression. Obesity Research, 3(S4), 477S-480S. https://doi.org/10.1002/j.1550-

8528.1995.tb00215.x

[10] Costarelli, V., \& Patsai, A. (2012). Academic examination stress increases disordered eating symptomatology in female university students. Eating and Weight Disorders - Studies on Anorexia, Bulimia and Obesity, 17(3), e164-e169. https://doi.org/10.1007/bf03325343

[11] LaMattina, Stephanie M., "Examining the Role of Stress in Binge Eating Disorder" (2008). Electronic Theses and Dissertations. 52.

https://digitalcommons.library.umaine.edu/etd/52

[12] Hale, A., Rieger, E., \& Russell, J. (2014). A qualitative investigation into the relationship between stress and eating disordered behaviours in patients with anorexia nervosa. Journal of Eating Disorders, 2(S1). https://doi.org/10.1186/20502974-2-s1-o49

[13] Ball, K., Lee, C., \& Brown, W. (1999). Psychological Stress and Disordered Eating: An Exploratory Study with Young Australian Women. Women \& Health, 29(2), 1-15. https://doi.org/10.1300/j013v29n02_01

[14] Anderson, Jenna K., "The relation between disordered eating, stress, and anxiety in first-year college women" (2019). Honors Program Theses. 390.

https://scholarworks.uni.edu/hpt/390

[15] Depression Anxiety Stress Scales - DASS. (2018, June 26). DASS.

http://www2.psy.unsw.edu.au/groups/dass/

[16] Tran, T. D., Tran, T., \& Fisher, J. (2013). Validation of the depression anxiety stress scales (DASS) 21 as a screening instrument for depression and anxiety in a rural community-based cohort of northern Vietnamese women. BMC Psychiatry, 13(1). https://doi.org/10.1186/1471-244x-13-24
[17] Berg, K. C., Peterson, C. B., Frazier, P., \& Crow, S. J. (2011). Convergence of scores on the interview and questionnaire versions of the Eating Disorder Examination: A meta-analytic review. Psychological Assessment, 23(3), 714-724. https://doi.org/10.1037/a0023246

[18] Luce, K.H. and Crowther, J.H. (1999), The reliability of the eating disorder examinationSelf - report questionnaire version (EDE - Q). Int. J. Eat. Disord., 25: 349-351. https://doi.org/10.1002/(SICI)1098108X(199904)25:3<349::AID-EAT15>3.0.CO;2$\mathrm{M}$

[19] JJ, P. (2016). Disordered Eating Patterns in University Students and Links with Stress Coping; a Literature Review and Discussion. Advanced Practices in Nursing, 01(01). https://doi.org/10.4172/2573-0347.1000108

[20] Vardar, E., Vardar, S. A., \& Kurt, C. (2007). Anxiety of young female athletes with disordered eating behaviors. Eating Behaviors, 8(2), 143-147. https://doi.org/10.1016/j.eatbeh.2006.03.002

[21] Mora, F., Fernandez Rojo, S., Banzo, C., \& Quintero, J. (2017). The impact of self-esteem on eating disorders. European Psychiatry, 41(S1), S558. https://doi.org/10.1016/j.eurpsy.2017.01.802

[22] Polivy, J., \& Herman, C. (2005). Mental Health and Eating Behaviours: A Bi-directional Relation. Canadian Journal of Public Health / Revue Canadienne De Sante'e Publique, 96, S43-S46. http://www.jstor.org/stable/41994472

[23] Shimizu, N., Oomura, Y., \& Kai, Y. (1989). Stressinduced anorexia in rats mediated by serotonergic mechanisms in the hypothalamus. Physiology \& Behavior, 46(5), 835-841. https://doi.org/10.1016/0031-9384(89)90045-0

[24] Bissada, H. (2019). Book Review: The DBT Solution for Emotional Eating. A Proven Program to Break the Cycle of Bingeing and Out-of-Control Eating. The Canadian Journal of Psychiatry, 17-18, 070674371986298. https://doi.org/10.1177/0706743719862983

[25] Schmalbach, I., Herhaus, B., Pässler, S., Runst, S., Berth, H., Wolff-Stephan, S., \& Petrowski, K. (2020). Cortisol reactivity in patients with anorexia nervosa after stress induction. Translational Psychiatry, 10(1). https://doi.org/10.1038/s41398020-00955-7 